PierCe, A. H. (1901). Studies in auditory and visual space perception. New York: Longmans Green.

Quina-Holland, K. (1977). Spatial distortions within the Poggendorff figure and its variants: A parametric analysis. Perception \& Psychophysics, 21, 118-124.

Restle, F. (1969). Illusions of bent line. Perception \& Psychophysics, 5, 273-274.

Restle, F., Decker, J. (1977). Size of the Mueller-Lyer illusion as a function of its dimensions: Theory and data. Perception \& Psychophysics, 21, 489-503.

Wilson, A. E., \& Pressey, A. W. (1976). The role of apparent distance in the Poggendorff illusion. Perception \& Psychophysics, 20, 309-316.

(Manuscript received August 30, 1988;

revision accepted for publication November 10, 1988.)

\title{
Announcement
}

\section{4th Annual Boston University Conference on Language Development October 13, 14, and 15, 1989}

The 14th Annual Boston University Conference on Language Development is scheduled for October 13, 14 , and 15,1989 . The keynote speaker will be William Labov of the University of Pennsylvania.

Sessions will focus on the following central themes: American Sign Language; Literacy in Theory and in Practice (literacy and ideology, literacy at school, in the humanities, in the workplace, minorities' interpretation, sociocultural approaches); Language Acquisition (theories of evidence, neural maturation); First Language Acquisition (including principles and parameters, acquisition of LF, irregular phenomena, phonology); and Second Language Acquisition (including age factors, parameter setting, and sociocultural factors).

For further information and a preliminary program, please contact Conference Committee, Conference on Language Development, Boston University, 605 Commonwealth Ave., Boston, MA 02215 (telephone: 617-353-3085). 